\title{
UII/GPR14 is involved in NF-кB-mediated colonic inflammation in vivo and in vitro
}

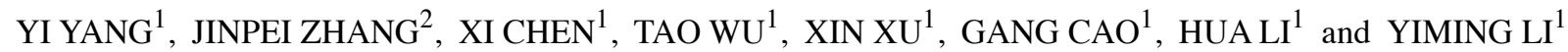 \\ ${ }^{1}$ Department of General Surgery, Second Hospital of Xi'an Jiaotong University, Xi'an, Shaanxi 710004; \\ ${ }^{2}$ Department of Encephalopathy, Hospital of Shaanxi University of Chinese Medicine, Xianyang, Shaanxi 712000, P.R. China
}

Received February 23, 2016; Accepted May 4, 2016

DOI: 10.3892/or.2016.5069

\begin{abstract}
The present study was conducted to investigate the molecular mechanism of urotensin II (UII) and its receptor, G protein-coupled receptor 14 (GPR14), in colonic inflammation. Urantide, a special antagonist of GPR14, and GPR14-siRNA were used to inhibit GPR14 signaling in dextran sulfate sodium (DSS)-induced inflammation in mice and Caco- 2 cells. The results showed that urantide alleviated rectal bleeding, histological injury and production of interleukin (IL)-17 and tumor necrosis factor- $\alpha$ (TNF- $\alpha$ ) caused by DSS in mice. GPR14-siRNA transfection subsequent with GPR14 inhibition reduced DSS-induced interferon- $\gamma$ (IFN)- $\gamma$ production in Caco- 2 cells. Meanwhile, both in vivo and in vitro data demonstrated that inhibition of UII/GPR14 alleviated nuclear factor $-\kappa \mathrm{B}(\mathrm{NF}-\kappa \mathrm{B})$ activation caused by DSS. In conclusion, UII/GPR14 signaling was involved in the DSS-induced colonic inflammation and its inhibition may serve as a potential therapeutic target, which may be associated with the $\mathrm{NF}-\kappa \mathrm{B}$ signaling pathway.
\end{abstract}

\section{Introduction}

Urotensin II (UII) and its receptor, G protein-coupled receptor 14 (GPR14), are widely expressed throughout the cardiovascular, pulmonary, central nervous, renal and metabolic systems $(1,2)$. UII/GPR14 signaling has been reported to be involved in various biological functions under both physiological and pathological conditions, such as enhancing foam cell formation, modulating insulin and catecholamine release, and regulating food intake (3). Meanwhile, elevated plasma levels of UII and expression of UII and UT have been noted in various diseased conditions, including hypertension, atherosclerosis, heart failure,

Correspondence to: Professor Yiming Li or Professor Tao Wu, Department of General Surgery, Second Hospital of Xi'an Jiaotong University, 157 Xi-wu Road, Xi'an, Shaanxi 710004, P.R. China

E-mail: liym0731@yeah.net

E-mail: wutao228@163.com

Key words: UII/GPR14, inflammation, NF-кB, mice, Caco-2 pulmonary hypertension, diabetes, renal failure and metabolic syndrome (3), suggesting a potential marker of disease activity. Meanwhile, pharmacological and genetic inhibition of the UII/GPR14 signaling pathway has been reported to serve as a protective mechanism in various pathological conditions (4), such as liver inflammation, ischemia-reperfusion injury and pulmonary arterial hypertension (5-7).

Recent studies suggest a potential immune inflammatory function of the UII/GPR14 system (8). In lipopolysaccharide challenged mice, inhibition of UII/GPR14 signaling by urantide treatment markedly alleviated the production of pro-inflammatory cytokines such as tumor necrosis factor- $\alpha$ (TNF- $\alpha$ ), interleukin (IL) $-1 \beta$ and interferon- $\gamma($ IFN- $\gamma$ ) via inactivation of the nuclear factor $-\kappa \mathrm{B}(\mathrm{NF}-\kappa \mathrm{B})$ pathway (9), which is known to be a major pro-inflammatory transcription factor controlling a wide number of genes, including cytokines (10). Meanwhile, urantide, a special antagonist of GPR14, has also been demonstrated to attenuate the inflammatory response via inhibition of p38 mitogen-activated protein kinase phosphorylation in lipopolysaccharide (LPS)stimulated Kupffer cells (9). However, UII/GPR14 signaling in intestinal inflammation and the potential therapeutic function in intestinal inflammatory disease are still obscure. Thus, in the present study, we investigated UII/GPR14 expression and the effects of inhibition of UII/GPR14 via urantide treatment on dextran sulfate sodium (DSS)-induced inflammation in mice and Caco- 2 cells.

\section{Materials and methods}

Animal model and groups. Thirty female Kunming mice (weighing, 23.14 $\pm 1.37 \mathrm{~g}$ ) were randomly assigned into three groups: a control group (control, $n=10$ ), a DSS-treated group (DSS, $\mathrm{n}=10$ ) in which mice received 5\% DSS (Kayon Biotechnology Co., Ltd., Shanghai, China) instead of tap water for 7 days to establish an inflammatory bowel disease (IBD) model, and a urantide group (DSS + UR, $n=10)$ in which mice received 5\% DSS and an intravenous injection of $0.6 \mathrm{mg} / \mathrm{kg}$ urantide (Peptides, Louisville, KY, USA) dissolved in saline. The control and untreated challenged animals received the same volume of saline alone. The dosage of urantide used in the present study was according to a previous study (4). All mice were housed in polycarbonate cages in a room with controlled temperature $\left(25 \pm 3^{\circ} \mathrm{C}\right)$, humidity $(50 \pm 5 \%)$ and a 
$12 \mathrm{~h}$ cycle of light and dark. They were allowed free access to laboratory strip chows throughout the experimental period.

After the experimental period, each animal was weighted to calculate average weight gain, and then each mouse was sacrificed and colon length and weight were measured. In addition, colon tissues from each mice were harvested and immediately frozen in liquid nitrogen and stored at $-70^{\circ} \mathrm{C}$ for subsequent gene expression and western blot analyses. The present study was conducted according to the guidelines of the Declaration of Helsinki and all procedures involving animal subjects were approved by the Animal Welfare Committee of the Department of Gastroenterology and Yantai Municipal Laiyang Central Hospital.

Clinical evaluation of DSS colitis. Rectal bleeding and diarrhea were monitored daily. The appearance of blood in the stool was measured by hemoccult tests (Beckman Coulter), and was given a score from $0-4$, defined as follows: 0 for no blood; 2 for positive hemoccult; and 4 for gross bleeding. The severity of diarrhea was given a score from 0-4, defined as follows: 0 for well-formed pellets; 2 for pasty and semi-formed stools; and 4 for liquid stools (11). All clinical scorings were performed in a blinded manner.

Histomorphometry determination. The morphological evaluation after DSS treatment was carried out using hematoxylin and eosin (H\&E) staining according to a previous study (12). Briefly, one piece of each colon sample $(0.5 \mathrm{~cm})$ was maintained in $4 \%$ neutral buffered $10 \%$ formalin, processed using routine histological methods, and mounted on paraffin blocks. Six-micrometer-thick sections were cut and stained with H\&E. All specimens were examined under a light microscope (Nikon, Tokyo, Japan).

The histological examination was performed in a blinded manner using a scoring system, previously validated and described (13). Three independent parameters were measured: severity of inflammation (0-3: none, slight, moderate and severe), depth of injury (0-3: none, mucosal, mucosal and submucosal and transmural), crypt damage $(0-4$, none, basal 1/3 damaged, basal 2/3 damaged, only surface epithelium intact, entire crypt and epithelium lost) and percentage of the involved area (0-4: 0\%, 1-10\%, 11-25\%, 26-50\% and 51-100\%). All scores on the individual parameters together could result in a total score ranging from 0 to 14 .

Cytokines. Intestinal segments were fractured using an ultrasonic disrupter (Bandelin, Berlin, Germany) and homogenized in RIPA buffer (Takara, Tokyo, Japan). In addition, the homogenates were centrifugated at 10,000 rpm for $20 \mathrm{~min}$, and the supernatants were used for further analysis.

IL-1 $\beta$, IL-10, IL-17, TNF- $\alpha$ and IFN- $\gamma$ were quantified using an enzyme-linked immunosorbent assay (ELISA) kit (R\&D Systems, Inc., Minneapolis, MN, USA) according to the manufacturer's protocol.

$N F-\kappa B$ activity. Colonic $\mathrm{NF}-\kappa \mathrm{B}$ activity was measured according to ELISA kits (Cell Biolabs, San Diego, CA, USA).

Cell culture and treatment. Human colorectal adenocarcinoma-derived intestinal epithelial cells (Caco-2) were obtained from the American Type Culture Collection (ATCC; Manassas, VA, USA) and grown in Dulbecco's modified Eagle's medium (DMEM)/F12 supplemented with $1 \mathrm{mM}$ sodium pyruvate, $20 \%$ fetal bovine serum (FBS) (HyClone, Logan, UT, USA), and $50 \mathrm{U} / \mathrm{ml}$ penicillin-streptomycin. The cells were then treated with $2 \%$ DSS for 4 days to induce inflammation according to a previous study (14).

siRNA transfection. Human GPR14 siRNA was obtained from Guangzhou RiboBio and transfected into cells using Lipofectamine RNAiMAX reagent according to the manufacturer's instructions (Invitrogen, Carlsbad, CA, USA). After transfection for $48 \mathrm{~h}$, the medium over the cells was changed before subsequent treatments.

Real-time PCR. Total RNA was isolated from liquid nitrogen pulverized tissues with TRIzol reagent, and then treated with DNase I (both from Invitrogen) according to the manufacturer's instructions. Synthesis of the first strand (cDNA) was performed with oligo(dT) ${ }_{20}$ and SuperScript II reverse transcriptase (Invitrogen). Primers were designed with Primer 5.0 according to the gene sequence of mouse to produce an amplification product. The primer sets used were as follows: $\beta$-actin, F, GTCCACCTTCCAGCAGATGT and R, GAAAGGGTGT AAAACGCAGC; IL-1 $\beta$ F, CTGTGACTCGTGGGATGATG and R, GGGATTTTGTCGTTGCTTGT; IL-6 F, TGCAAGA GACTTCCATCCAGT and R, GTGAAGTAGGGAAGGCCG; IL-10 F, ACAGCCGGGAAGACAATAAC and R, CAGCTG GTCCTTTGTTTGAAAG; IL-17 F, TACCTCAACCGTT CCACGTC and R, TTTCCCTCCGCATTGACAC; IFN- $\gamma$ F, ATGAACGCTACACACTGCATCTTGGCTT and R, CCT CAAACTTGGCAATACTCATGAATGC; TNF- $\alpha$ F, AGGC ACTCCCCCAAAAGAT and R, TGAGGGTCTGGGCCAT AGAA. Real-time PCR was performed according to previous studies $(15,16)$. Relative expression was normalized and expressed as a ratio to the expression in the control group.

Western blotting. Proteins were extracted with protein extraction reagents in accordance with the manufacturer's instructions (Thermo Fisher Scientific, Inc., Waltham, MA, USA). Proteins from each sample $(30 \mu \mathrm{g})$ were separated by SDS-polyacrylamide gel electrophoresis and electrophoretically transferred to a polyvinylidene difluoride (PVDF) membrane (Bio-Rad, Hercules, CA, USA). The membranes were blocked in $7 \%$ evaporated milk, diluted in Tris-buffered saline containing $0.1 \%$ Tween-20 (TBS-226T) at room temperature for at least $2 \mathrm{~h}$, and then incubated overnight at $4^{\circ} \mathrm{C}$ with the following primary antibodies: UII (ab194676), GPR14

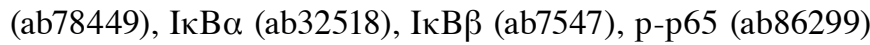
and NF-кBp65 (ab7970) (Abcam, Inc., Cambridge, MA, USA). Mouse $\beta$-actin antibody (Sigma) was used for protein loading control. After primary antibody incubation, the membranes were washed with TBS-T and incubated with alkaline phosphatase-conjugated anti-mouse or anti-rabbit IgG antibodies (Promega, Madison, WI, USA) for $2 \mathrm{~h}$ at room temperature. The membranes were washed with TBS-T followed by three washes with TBS; signals were detected by the addition of 5-bromo-4-chloro-3-238 indolylphosphate/nitroblue tetrazolium (BCIP/NBT) solution (Sigma), then quantified and digitally analyzed using ImageJ program (NIH, Bethesda, 

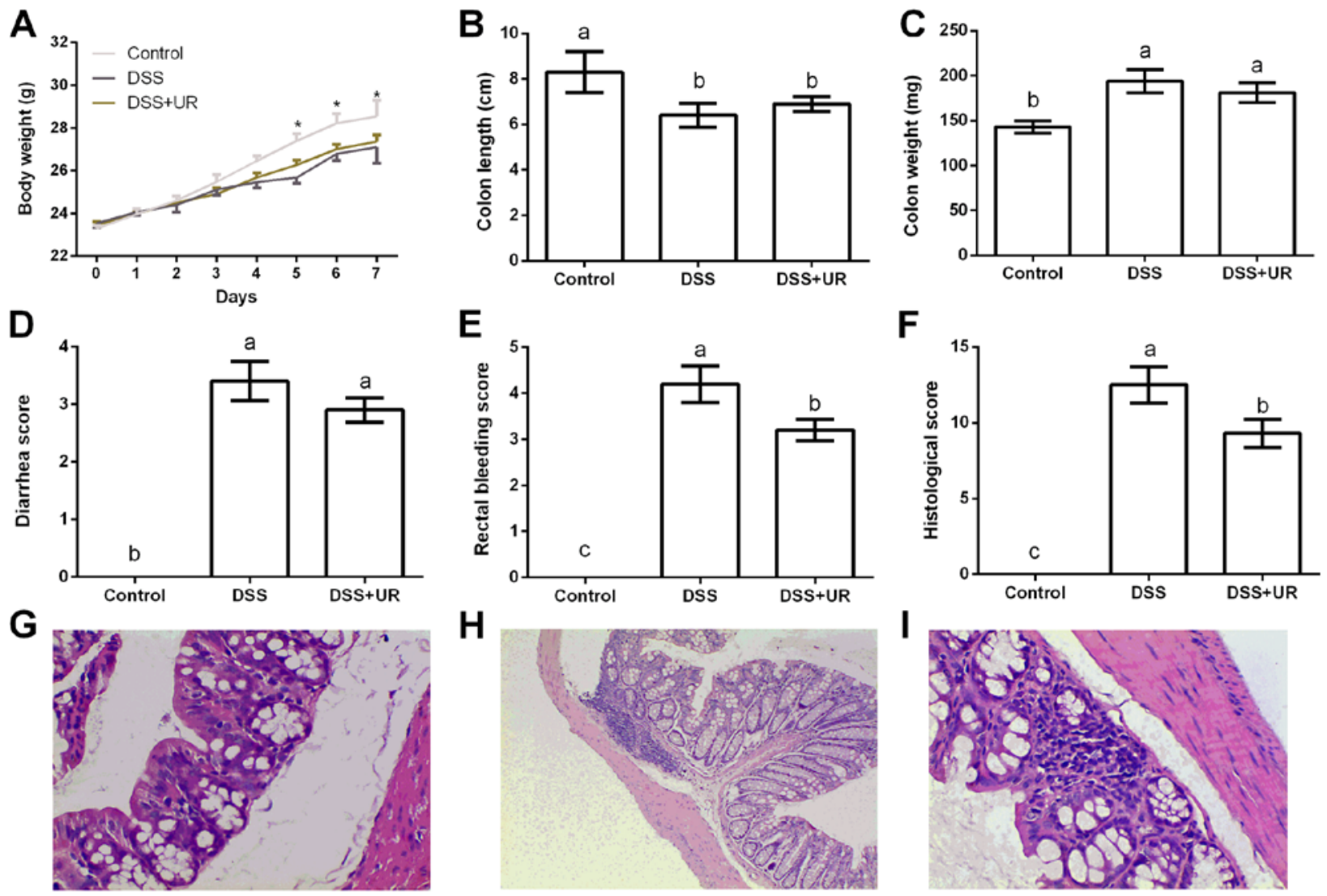

Figure 1. Effects of urantide injection on clinical parameters and histological structure in DSS-challenged mice. (A) Body weight (g). (B) Colonic length (cm). (C) Colonic weight (g). (D) Diarrhea score. (E) Rectal bleeding score. (F) Histological score. (G-I) Histological staining via H\&E staining (magnification, $\mathrm{x} 400)$. Data are presented as mean \pm SEM. The values having different superscript letters are significantly different $(\mathrm{P}<0.05 ; \mathrm{n}=8)$. "significant difference compared with the DSS and DSS+UR groups.

MD, USA). The intensity of each band was measured and subtracted from the background. The expression ratio of target proteins was normalized against $\beta$-actin (17).

Statistical analysis. All statistical analyses were performed using SPSS 17.0 software. Group comparisons were performed using one-way analysis of variance (ANOVA) to test homogeneity of variances via Levene's test followed by Tukey's multiple comparison test. Values in the same row with different superscripts are significant $(\mathrm{P}<0.05)$, while values with the same superscripts are not significantly different $(\mathrm{P}>0.05)$.

\section{Results}

Clinical indices. As shown at Fig. 1, altered body weight, colon length and weight, rectal bleeding and histological scores indicated a colitis model, which is consistent with previous studies $(18,19)$. Compared with the IBD group, urantide injection markedly reduced rectal bleeding and histological scores after DSS treatment, suggesting a protective role in the colitis model.

Inflammatory response in mice. In the present study, ileum and colon samples were collected to test cytokine concentrations. The results exhibited that DSS treatment increased IL-17, TNF- $\alpha$ and IFN- $\gamma$ levels in the ileum, and IL-1 $\beta$, IL-17, TNF- $\alpha$ and IFN- $\gamma$ levels in the colon $(\mathrm{P}<0.05)($ Table I). Compared
Table I. Effects of urantide injection on pro-inflammatory cytokines (pg/ml) in DSS-challenged mice.

\begin{tabular}{lccl}
\hline Cytokine & Control & DSS & \multicolumn{1}{c}{ DSS + UR } \\
\hline Ileum & & & \\
IL-1 $\beta$ & $363.16 \pm 26.14$ & $392.28 \pm 13.75$ & $389.38 \pm 28.17$ \\
IL-10 & $103.82 \pm 8.15$ & $91.73 \pm 10.65$ & $112.53 \pm 9.67$ \\
IL-17 & $175.39 \pm 20.33^{\mathrm{b}}$ & $253.19 \pm 17.16^{\mathrm{a}}$ & $207.27 \pm 11.56^{\mathrm{a}, \mathrm{b}}$ \\
TNF- $\alpha$ & $253.38 \pm 26.47^{\mathrm{b}}$ & $297.16 \pm 24.85^{\mathrm{a}}$ & $313.47 \pm 25.14^{\mathrm{a}}$ \\
IFN- $\gamma$ & $293.29 \pm 27.92^{\mathrm{b}}$ & $431.39 \pm 22.55^{\mathrm{a}}$ & $361.54 \pm 31.54^{\mathrm{b}}$ \\
Colon & & & \\
IL-1 $\beta$ & $317.54 \pm 14.85^{\mathrm{b}}$ & $475.65 \pm 62.42^{\mathrm{a}}$ & $418.82 \pm 19.46^{\mathrm{a}}$ \\
IL-10 & $86.26 \pm 6.59$ & $116.87 \pm 14.09$ & $105.49 \pm 11.65$ \\
IL-17 & $117.69 \pm 19.74^{\mathrm{b}}$ & $218.65 \pm 19.49^{\mathrm{a}}$ & $151.11 \pm 26.49^{\mathrm{b}}$ \\
TNF- $\alpha$ & $236.59 \pm 24.49^{\mathrm{b}}$ & $378.65 \pm 34.57^{\mathrm{a}}$ & $295.34 \pm 24.37^{\mathrm{a}, \mathrm{b}}$ \\
IFN- $\gamma$ & $251.68 \pm 15.94^{\mathrm{c}}$ & $476.15 \pm 36.11^{\mathrm{a}}$ & $387.12 \pm 25.43^{\mathrm{b}}$ \\
\hline
\end{tabular}

DSS, dextran sulfate sodium; UR urantide; IL, interleukin; TNF- $\alpha$, tumor necrosis factor- $\alpha$; IFN- $\gamma$, interferon- $\gamma$. Data are presented as mean \pm SEM. The values having different superscripted letters are significantly different $(\mathrm{P}<0.05 ; \mathrm{n}=6$ or 8$)$.

with the IBD group, urantide significantly reduced ileal IFN- $\gamma$ and colonic IL-17 and IFN- $\gamma$ concentrations. 

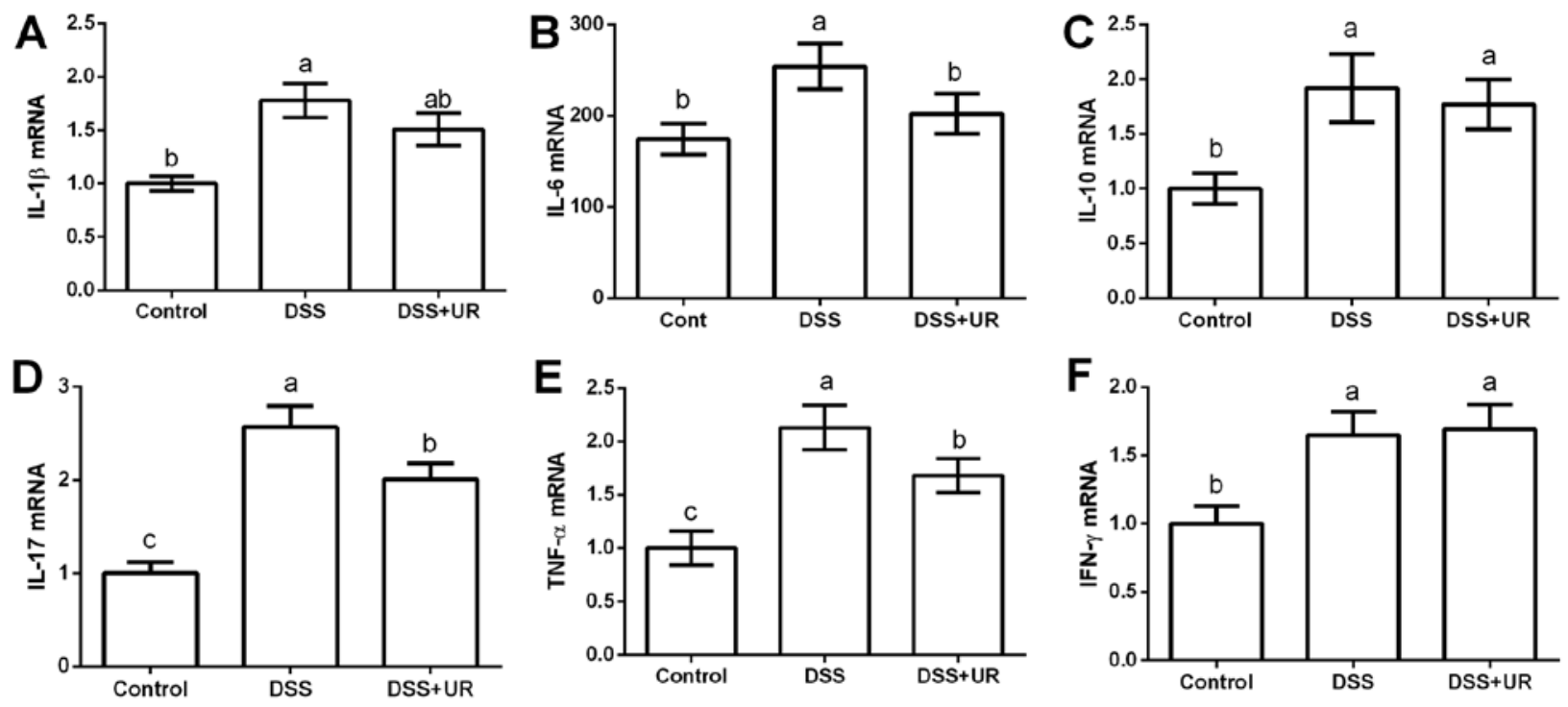

Figure 2. Effects of urantide injection (UR) on the mRNA levels of pro-inflammatory cytokines, (A) IL-1 $\beta$, (B) IL-6, (C) IL-10, (D) IL-17, (E) TNF- $\alpha$ and (F) IFN- $\gamma$ in DSS-challenged mice as determined by RT-PCR. Data are presented as mean \pm SEM. The values having different superscripted letters are significantly different $(\mathrm{P}<0.05 ; \mathrm{n}=6$ or 8$)$.
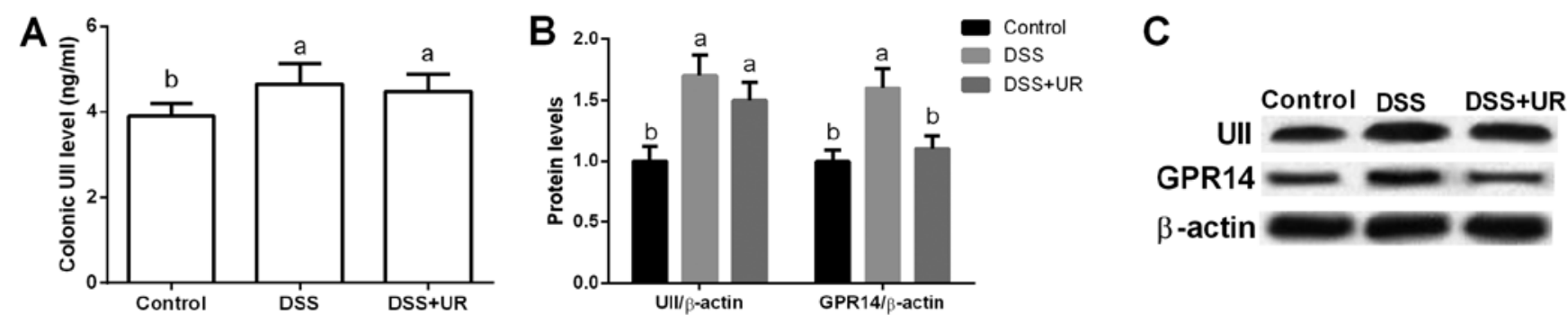

Figure 3. Effects of urantide injection (UR) on (A) colonic UII abundance and (B and C) protein expression in DSS-challenged mice. Data are presented as mean \pm SEM. The values having different superscripted letters are significantly different $(\mathrm{P}<0.05 ; \mathrm{n}=6$ or 8$)$.
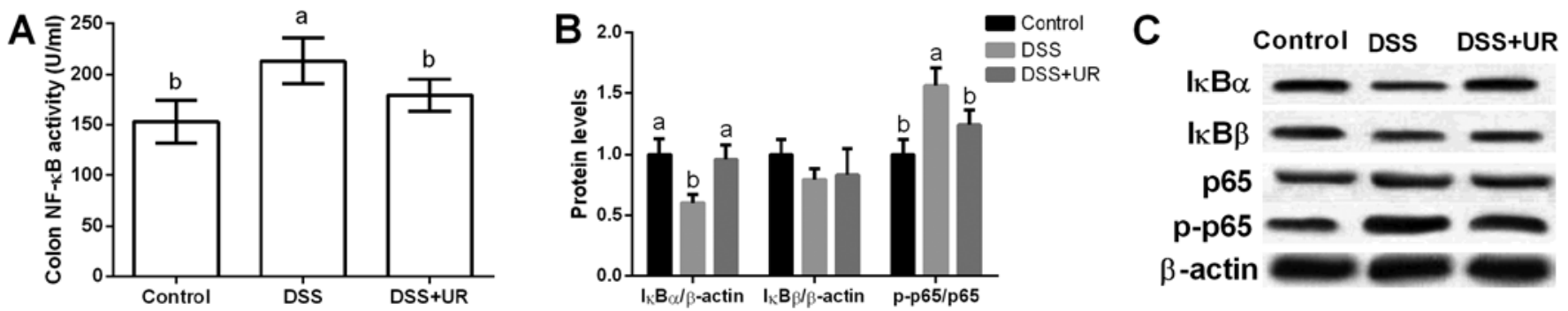

Figure 4. Effects of urantide injection (UR) on (A) colonic NF- $\kappa$ B activity and (B and C) protein expression in DSS-challenged mice. Data are presented as mean \pm SEM. The values having different superscripted letters are significantly different $(\mathrm{P}<0.05 ; \mathrm{n}=6$ or 8$)$.

Meanwhile, colonic expression of cytokines were further determined via RT-PCR (Fig. 2). The results showed that colonic IL-1 $\beta$, IL-10, IL-17, TNF- $\alpha$ and IFN- $\gamma$ were significantly upregulated in the IBD group $(\mathrm{P}<0.05)$. Urantide injection markedly downregulated IL-17 and TNF- $\alpha$ expression $(\mathrm{P}<0.05)$.

UII levels and GPR14 expression in mice. Urantide was used to inhibit UII/GPR14 signaling in the present study. We found that colonic UII levels were significantly higher in the IBD group when compared to that in the control group $(\mathrm{P}<0.05)$, while urantide treatment failed to influence the colonic UII concentration ( $\mathrm{P}>0.05$ ) (Fig. 3).

Meanwhile, our data exhibited that UII and GPR14 were significantly upregulated after DSS treatment $(\mathrm{P}<0.05)$ (Fig. 3), suggesting that UII/GPR14 is involved in DSS-induced inflammation. Although we failed to observe any significant difference in colonic UII expression after urantide injection, urantide markedly inhibited GPR14 expression $(\mathrm{P}<0.05)$ (Fig. 3). 
A
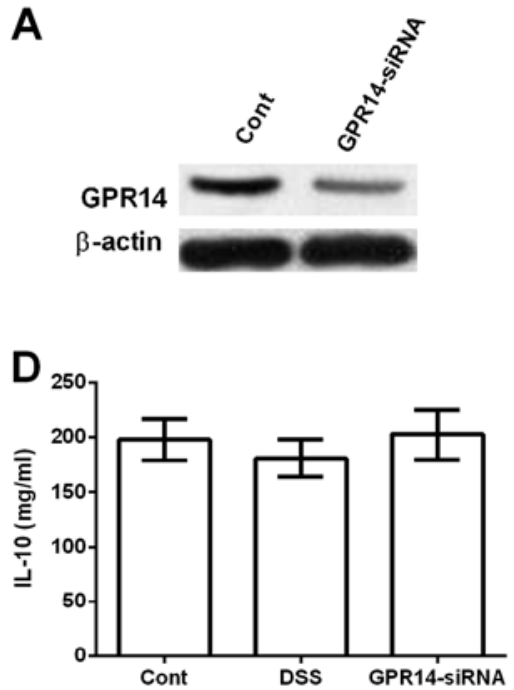

G

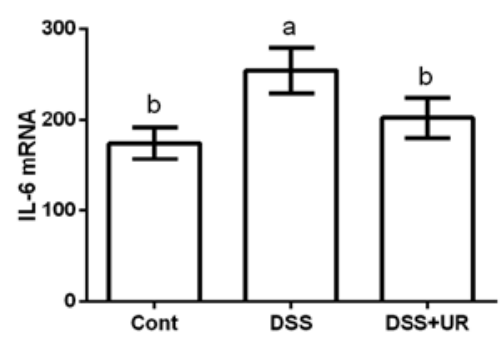

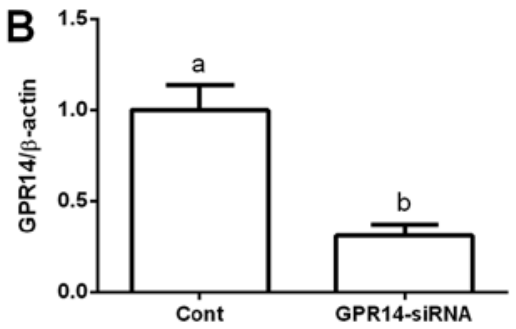

E

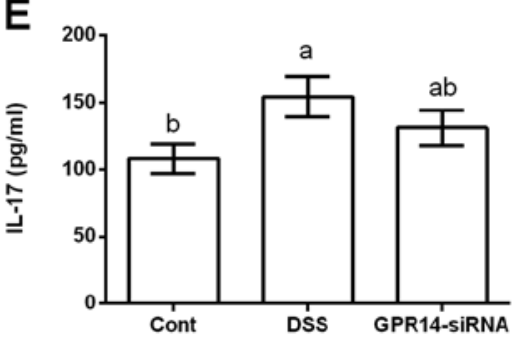

H

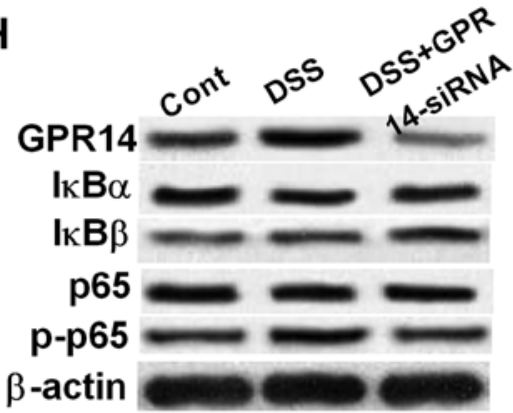

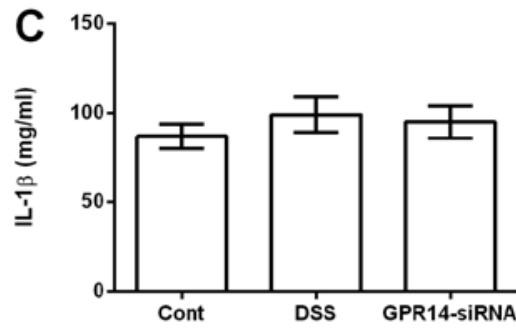
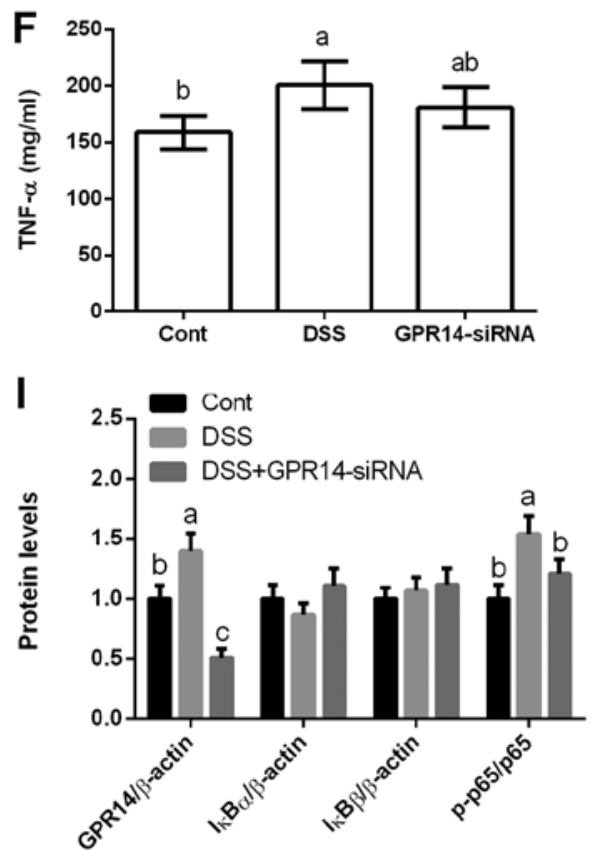

Figure 5. Effects of GPR14-siRNA on (A and B) GPR14 and pro-inflammatory cytokines, (C) IL-1 $\beta$, (D) IL-10, (E) IL-17, (F) TNF- $\alpha$ and (G) IL-6 and ( $\mathrm{H}$ and $\mathrm{I})$ protein expression in DSS-challenged Caco-2 cells. Data are presented as mean \pm SEM. The values having different superscripted letters are significantly different $(\mathrm{P}<0.05 ; \mathrm{n}=3-6)$.

$N F-\kappa B$ signal in mice. Colonic $\mathrm{NF}-\kappa \mathrm{B}$ activity was significantly increased after DSS treatment, while urantide markedly reduced $\mathrm{NF}-\kappa \mathrm{B}$ activity in the mice $(\mathrm{P}<0.05)$ (Fig. 4). Furthermore, colonic NF- $\kappa \mathrm{B}$ signal-related proteins (i.e. I $\kappa \mathrm{B} \alpha, \mathrm{I} \kappa \mathrm{B} \beta$, p 65 and p-p65) were assessed and the results showed that DSS significantly increased p65 phosphorylation and urantide treatment inhibited p65 activation ( $\mathrm{P}<0.05)$ (Fig. 4). IкB is an inhibitory protein of the $\mathrm{NF}-\kappa \mathrm{B}$ signaling pathway, and we found that DSS markedly inhibited I $\kappa \mathrm{B} \alpha$ expression, while urantide alleviated $\mathrm{I} \kappa \mathrm{B} \alpha$ upregulation caused by DSS exposure.

UII/GPR14 mediates NF- $\kappa B$ signaling in Caco-2 cells. The in vivo data indicated that UII/GPR14 is involved in DSS-induced inflammatory response in mice. Thus, we further validated the effect of UII/GPR14 in vitro via GPR14-siRNA transfection. The results exhibited that GPR14siRNA transfection markedly reduced GPR14 expression, which further inhibited DSS-induced IFN- $\gamma$ production $(\mathrm{P}<0.05)$ (Fig. 5).

The western blot results showed that DSS exposure also increased GPR14 expression in vitro and inhibition of GPR14 via GPR14-siRNA transfection markedly reduced GPR14 expression $(\mathrm{P}<0.05)$ (Fig. 5). Yet, GPR14-siRNA transfection failed to influence I $\mathrm{B} \alpha$ and $\mathrm{I} \kappa \mathrm{B} \beta$, and GPR14 downregulation significantly inhibited p65 phosphorylation $(\mathrm{P}<0.05)$ (Fig. 5).

\section{Discussion}

Previous studies have suggested that the UII/GPR14 signaling pathway is involved in pro-inflammatory responses via mediating pro-inflammatory cytokine expression $(4,9,20,21)$. In the present study, we used urantide, a special antagonist of GPR14, to block GPR14 and the results indicated that GPR14 inhibition alleviated DSS-induced colitis in mice evidenced by reduced rectal bleeding and histological injury, indicating a protective role of urantide in the colitis model.

Pro-inflammatory cytokines and inflammation response in the gastrointestinal tract play a vital role in the progression of IBD (10,22-25). However, the effect of UII/GPR14 signaling on DSS-induced pro-inflammatory cytokine generation is not fully understood. In the present study, we found marked increases in pro-inflammatory cytokine (i.e. IL-1 $\beta$, IL-10, IL-17, TNF- $\alpha$ and IFN- $\gamma$ ) levels and expression in the DSS challenged mice. Inhibition of the UII/GPR14 signal using urantide significantly reduced IL-17 and TNF- $\alpha$ generation, suggesting that the releases of these cytokines may be a consequence of UII/UTR system activation induced by DSS exposure. In lipopolysaccharide/D-galactosamine-induced liver inflammation, urantide has been demonstrated to prevent increases in pro-inflammatory cytokines such as IL-1 $\beta$, TNF- $\alpha$ and IFN- $\gamma$ (4). Meanwhile, the in vitro data revealed 
that urantide treatment alleviated IFN- $\gamma$ production caused by DSS in Caco- 2 cells. Thus, we speculated that UII/GPR14 signaling may be involved in DSS-induced inflammation and inhibition of UII/GPR14 may exhibit an anti-inflammatory function in in vivo and in vitro models.

UII/GPR14 signaling has been confirmed to mediate inflammatory response (9), while activity of the UII/GPR14 signal has never been evaluated in DSS-induced inflammation. In the present study, we found that the UII/GPR14 signal was significantly activated after DSS exposure evidenced by the upregulation of UII and GPR14. Similarly, Liang et al also reported that liver UII and GPR14 expression and serum UII levels were markedly enhanced in lipopolysaccharide/D-galactosamine-induced liver inflammation in mice (4). Meanwhile, both urantide and GPR14 siRNA transfection inhibited GPR14 expression, which further alleviated DSS-induced inflammation in mice and Caco-2 cells.

To investigate the mechanisms underlying the protective effect of UII/GPR14 signal inactivation on DSS-induced inflammation, we determined the effect of urantide and GPR14 siRNA transfection on signaling molecules of the $N F-\kappa B$ pathway in the colon and Caco- 2 cells. The NF- $\mathrm{B}$ signaling pathway has been found to be associated with the expression of various cytokines and chemokines in response to cellular stimuli such as inflammation and oxidative stress (26-29). In the present study, $\mathrm{NF}-\kappa \mathrm{B}$ signaling was activated after DSS treatment in vivo and in vivo, while inhibition of the UII/ GPR14 signal via urantide or GPR14 siRNA transfection significantly inactivated $\mathrm{NF}-\kappa \mathrm{B}$ via reducing p65 phosphorylation. $\mathrm{NF}-\kappa \mathrm{B}$ activation requires $\mathrm{I} \kappa \mathrm{Bs}$, an inhibitory protein of NF- $\kappa \mathrm{B}(25,26,29)$. The present data revealed that urantide markedly alleviated the inhibitory effect of DSS on I $\mathrm{B} \alpha$. Thus, we concluded that UII/GPR14 may mediate I $\kappa \mathrm{B} \alpha$ / $\mathrm{NF}-\kappa \mathrm{B}$ signaling in DSS-induced inflammation. Inhibition of the NF- $\kappa \mathrm{B}$ signaling pathway has been indicated to be a potential therapeutic target in inflammatory diseases, including IBD. For example, inactivation of the $\mathrm{NF}-\kappa \mathrm{B}$ pathway was found to downregulate pro-inflammatory cytokine expression in an IBD murine model (30). Meanwhile, pyrrolidine dithiocarbamate, an antioxidant agent and NF- $\kappa \mathrm{B}$ inhibitor, has been confirmed to reverse the activation of the $N F-\kappa B$ signaling pathway and alleviate colonic inflammation caused by DSS treatment (31).

In conclusion, UII/GPR14 signaling is involved in DSS-induced inflammation in mice and Caco-2 cells. Inhibition of UII/GPR14 via urantide or GPR14 siRNA transfection alleviated DSS-induced inflammation and NF- $\kappa \mathrm{B}$ activity. Thus, the beneficial effect of UII/GPR14 inhibition on the inflammatory response may be associated with the $\mathrm{NF}-\kappa \mathrm{B}$ signaling pathway.

\section{References}

1. Ross B, McKendy K and Giaid A: Role of urotensin II in health and disease. Am J Physiol Regul Integr Comp Physiol 298: R1156-R1172, 2010.

2. Ong KL, Lam KS and Cheung BM: Urotensin II: Its function in health and its role in disease. Cardiovasc Drugs Ther 19: 65-75, 2005.

3. McDonald J, Batuwangala $\mathrm{M}$ and Lambert DG: Role of urotensin II and its receptor in health and disease. J Anesth 21: 378-389, 2007.
4. Liang DY, Liu LM, Ye CG, Zhao L, Yu FP, Gao DY, Wang YY, Yang ZW and Wang YY: Inhibition of UII/UTR system relieves acute inflammation of liver through preventing activation of NF- $\kappa$ B pathway in ALF mice. PLoS One 8: e64895, 2013.

5. Zhang JY, Chen ZW and Yao H: Protective effect of urantide against ischemia-reperfusion injury via protein kinase $\mathrm{C}$ and phosphtidylinositol 3'-kinase - Akt pathway. Can J Physiol Pharmacol 90: 637-645, 2012.

6. Zhao J, Yu QX, Kong W, Gao HC, Sun B, Xie YQ and Ren LQ: The urotensin II receptor antagonist, urantide, protects against atherosclerosis in rats. Exp Ther Med 5: 1765-1769, 2013.

7. Mei Y, Jin H, Tian W, Wang H, Wang H, Zhao Y, Zhang Z and Meng F: Urantide alleviates monocrotaline induced pulmonary arterial hypertension in Wistar rats. Pulm Pharmacol Ther 24: 386-393, 2011.

8. Birker-Robaczewska M, Boukhadra C, Studer R, Mueller C, Binkert $\mathrm{C}$ and Nayler O: The expression of urotensin II receptor (U2R) is up-regulated by interferon-gamma. J Recept Signal Transduct Res 23: 289-305, 2003.

9. Liu LM, Liang DY, Ye CG, Tu WJ and Zhu T: The UII/UT system mediates upregulation of proinflammatory cytokines through p38 MAPK and NF- $\kappa \mathrm{B}$ pathways in LPS-stimulated Kupffer cells. PLoS One 10: e0121383, 2015.

10. Hirai F and Matsui T: Status of food intake and elemental nutrition in patients with Crohn's disease. Integr Food Nutr Metab 2: 148-150, 2015.

11. Vlantis K, Polykratis A, Welz PS, van Loo G, Pasparakis M and Wullaert A: TLR-independent anti-inflammatory function of intestinal epithelial TRAF6 signalling prevents DSS-induced colitis in mice. Gut 65: 935-943, 2016.

12. Yin J, Duan J, Cui Z, Ren W, Li T and Yin Y: Hydrogen peroxide-induced oxidative stress activates $N F-\kappa B$ and Nrf2/Keap1 signals and triggers autophagy in piglets. RSC Advances 5: 15479-15486, 2015.

13. Ranganathan P, Jayakumar C, Li DY and Ramesh G: UNC5B receptor deletion exacerbates DSS-induced colitis in mice by increasing epithelial cell apoptosis. J Cell Mol Med 18: 1290-1299, 2014

14. Nighot P, Young K, Nighot M, Rawat M, Sung EJ, Maharshak N, Plevy SE, Ma T and Blikslager A: Chloride channel ClC-2 is a key factor in the development of DSS-induced murine colitis. Inflamm Bowel Dis 19: 2867-2877, 2013.

15. Yin J, Ren W, Liu G, Duan J, Yang G, Wu L, Li T and Yin Y: Birth oxidative stress and the development of an antioxidant system in newborn piglets. Free Radic Res 47: 1027-1035, 2013.

16. Yin J, Wu MM, Xiao H, Ren WK, Duan JL, Yang G, Li TJ and Yin YL: Development of an antioxidant system after early weaning in piglets. J Anim Sci 92: 612-619, 2014.

17. Yin J, Liu M, Ren W, Duan J, Yang G, Zhao Y, Fang R, Chen L, $\mathrm{Li}$ T and Yin Y: Effects of dietary supplementation with glutamate and aspartate on diquat-induced oxidative stress in piglets. PLoS One 10: e0122893, 2015.

18. Agren R, Otero JM and Nielsen J: Genome-scale modeling enables metabolic engineering of Saccharomyces cerevisiae for succinic acid production. J Ind Microbiol Biotechnol 40: 735-747, 2013.

19. Lee KH, Park M, Ji KY, Lee HY, Jang JH, Yoon IJ, Oh SS Kim SM, Jeong YH, Yun CH, et al: Bacterial $\beta$ - $(1,3)$-glucan prevents DSS-induced IBD by restoring the reduced population of regulatory T cells. Immunobiology 219: 802-812, 2014.

20. Shori AB and Baba AS: Fermented milk derives bioactive peptides with antihypertensive effects. Integr Food Nutr Metab 2: 178-181, 2015.

21. Zaki SA, Amin WSM and Nagi HM: The functional role of tomato and carrot on histopathological lesions of brain, small intestine and prostate in mice treated with acrylamide. Integr Food Nutr Metab 1: 114-118, 2014.

22. Sánchez-Fidalgo S, Cárdeno A, Sánchez-Hidalgo M, Aparicio-Soto $M$ and de la Lastra CA: Dietary extra virgin olive oil polyphenols supplementation modulates DSS-induced chronic colitis in mice. J Nutr Biochem 24: 1401-1413, 2013.

23. Scharl M, Vavricka SR and Rogler G: Review: new anti-cytokines for IBD: what is in the pipeline? Curr Drug Targets 14: 1405-1420, 2013.

24. Beloqui A, Coco R, Alhouayek M, Solinís MÁ, RodríguezGascón A, Muccioli GG and Préat V: Budesonide-loaded nanostructured lipid carriers reduce inflammation in murine DSS-induced colitis. Int J Pharm 454: 775-783, 2013. 
25. Choi A-J, Buisson N and Kim C-T: Digestion characteristics and kinetic analysis of bio-molecules in a simulated human intestinal system. Integr Food Nutr Metab 2: 189-192, 2015.

26. Yin J, Ren WK, Wu XS, et al: Oxidative stress-mediated signaling pathways: A review. J Food Agric Environ 11: 132-139, 2013.

27. Hendy HA-RE and Gemeai AROA-: Effect of broccoli intake on antioxidant in the liver and kidney tissues of hyperglycemic rats. Integr Food Nutr Metab 1: 83-86, 2014.

28. Mileva S, Galunska B, Gospodinova M, et al: Vitamin D3 status in children with acute diarrhea. Integr Food Nutr Metab 1: 1-6, 2014.

29. McCann MJ, Dalziel JE, Bibiloni R and Barnett MPG: An integrated approach to assessing the bio-activity of nutrients in vitro: The anti-oxidant effects of catechin and chlorogenic acid as an example. Integr Food Nutr Metab 2: 197-204, 2015.
30. Beneficial effects of THSG on acetic acid-induced experimental colitis: involvement of upregulation of PPAR- $\gamma$ and inhibition of the Nf-Kb inflammatory pathway. Molecules 16: 8552-8568, 2011.

31. Yin J, Wu M, Duan J, Liu G, Cui Z, Zheng J, Chen S, Ren W, Deng J, Tan X, et al: Pyrrolidine dithiocarbamate inhibits NF-kappaB activation and upregulates the expression of Gpx1, Gpx4, occludin, and ZO-1 in DSS-induced colitis. Appl Biochem Biotechnol 177: 1716-1728, 2015. 